\title{
Preparation, Characterization and Photocatalytic Activity of Titania Nanotube Arrays Decorated with Tungsten Trioxide
}

\author{
Mohamad Mohsen Momeni \\ Isfahan University of Technology, Isfahan 84156-83111, Iran
}

\begin{abstract}
Titania nanotube arrays decorated with $\mathrm{WO}_{3}(\mathrm{WTN})$ were fabricated by a chemical bath deposition (CBD) technique in combination with a pyrolysis process. The products were uniform and the amount of tungsten can be easily adjusted by the deposition time. The resultant hybrid nanotubes arrays were characterized by SEM, EDX and XRD. Results show that titania nanotubes with an internal diameter of the tubes 90 120 nm, an external diameter 120 160 nm, wall thickness in the range of 30 60 $\mathrm{nm}$ and a length of $39 \mu \mathrm{m}$ are grown on titanium substrate by anodizing. The tungsten trioxide is i decorated on the titania nanotubes, which enhances the photocatalytic activity of the WTN, as indicated by the efficient removal of C.I. Sulphur Red 14. The resultant composite films show better photocatalytic activity than the non-decorated nanotube arrays (TN) under visible light illumination.
\end{abstract}

Key words: nanotube; film; anodizing; tungsten; titania; photocatalyst

Titania nanotube arrays (TN) have been extensively investigated as photocatalysts for degradation of organic pollutants in water because of their favorable band-edge positions, strong optical absorption, superior chemical stability, photocorrosion resistance, and low cost ${ }^{[1-5]}$. Nevertheless, the intrinsic band gap of $\mathrm{TiO}_{2}(3.2 \mathrm{eV}$ for anatase and $3.0 \mathrm{eV}$ for rutile) restricts the absorption in the ultraviolet part of the solar spectrum. As UV light is only $4 \%$ of the solar spectrum, therefore it is highly desirable to tailor the band gap of $\mathrm{TiO}_{2}$ in such away so that it can absorb light in the visible region which accounts for about $45 \%$ of the solar energy ${ }^{[4]}$. Therefore, many groups have investigated how to narrow the band gap of $\mathrm{TiO}_{2}$ to maximize the utilization efficiency of solar energy and increase the yield of the electron-hole pair which is the key factor for the $\mathrm{TiO}_{2}$ applications. One effective approach is to dope different elements into $\mathrm{TiO}_{2}$, including metal or nonmetal elements ${ }^{[4-9]}$. Because $\mathrm{W}^{6+}$ has an ionic radius similar to that of $\mathrm{Ti}^{4+}, \mathrm{WO}_{3}$ can couple into $\mathrm{TiO}_{2}$ crystals in their co-crystallization process during annealing, resulting in a well doped WTN composite. Incorporating $\mathrm{WO}_{3}$ with $\mathrm{TiO}_{2}$ not only efficiently inhibits the recombination between the photogenerated holes and electrons but also reduces the band gap of $\mathrm{TiO}_{2}{ }^{[8]}$. In the present study, titania nanotube arrays decorated with tungsten trioxide (WTN) were fabricated via an efficient and easily accessible approach. The decoration of tungsten occurred homogenously and tungsten decorated titania nanotubes could be achieved by using chemical bath deposition (CBD) technique. The morphology and structure were characterized by field emission scanning electron microscopy (FE-SEM) and X-ray diffraction (XRD). Optical properties were investigated by UV-vis diffuse reflectance spectra. In addition, photocatalytic activity of WTN samples was evaluated through the degradation of C. I. Sulphur Red 14 (CISR) dye. The CISR is highly soluble in water and organic solvent ${ }^{[10]}$. Its chemical structure is given in Fig. 1 and its characteristics are given in Table 1.

\section{Experiment}

All chemicals were of analytical grade and used as received without further purification or treatment. All solutions were prepared with distilled water. Pieces of titanium metal

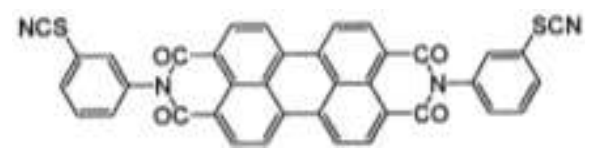

Fig.1 Structure of C. I. Sulphur Red 14 (CISR) 
Table 1 Characteristics of C. I. Sulphur Red 14 dye $^{[10]}$

\begin{tabular}{cc}
\hline Variable & Value \\
\hline Molecular formula & $\mathrm{C}_{38} \mathrm{H}_{16} \mathrm{~N}_{4} \mathrm{O}_{4} \mathrm{~S}_{2}$ \\
Molecular structure & Perylene class \\
Molecular mass $/ \mathrm{g} \cdot \mathrm{mol}^{-1}$ & 656.69 \\
$\lambda_{\max } / \mathrm{nm}$ & 565
\end{tabular}

Properties and applications

Red. Deep red powder. Used for cotton, hemp, viscose fabric dyeing

sheet (99.99\% purity, $1 \mathrm{~mm}$ thick) were cut into proper dimensions. Then obtained titanium electrodes were mechanically polished with different emery type abrasive papers (with the following grades: 80\#, 240\#, 800\#, 1200\#, and 2400\#), rinsed in a bath of distilled water, and then chemically etched by immersing in a mixture of $\mathrm{HF}$ and $\mathrm{HNO}_{3}$ acids for $30 \mathrm{~s}$. The ratio of $\mathrm{HF} / \mathrm{HNO}_{3} / \mathrm{H}_{2} \mathrm{O}$ in the mixture was 1:4:5 in volume. The last step of pretreatment was rinsing with distilled water. After cleaning, anodic films were grown from titanium by anodizing of titanium foil in a solution of glycerol $(90 \mathrm{~mL})$ containing $0.13 \mathrm{~mol} / \mathrm{L} \mathrm{NH}_{4} \mathrm{~F}$ and $10 \mathrm{~mL}$ distilled water at a constant voltage of $60 \mathrm{~V}$ for $6 \mathrm{~h}$ at room temperature using a platinum foil as cathode. After anodizing of titanium and preparation of titania nanotube arrays, tungsten were decorated on nanotubes by chemical bath deposition. The titania nanotubes (TN) were soaked in a $0.1 \mathrm{~mol} / \mathrm{L} \mathrm{H}_{2} \mathrm{SO}_{4}$ solution for $90 \mathrm{~min}$ followed by soaking in a $\mathrm{H}_{2} \mathrm{O} /$ ethanol (4:1) solution containing $0.05 \mathrm{~mol} / \mathrm{L} \mathrm{Na}_{2} \mathrm{WO}_{4}$ for different time at $70{ }^{\circ} \mathrm{C}$. Then, the samples were rinsed with distilled water and dried in air. Samples were annealed by heating at $400{ }^{\circ} \mathrm{C}$ for $2 \mathrm{~h}$, with a heating ramp of $1{ }^{\circ} \mathrm{C} / \mathrm{min}$ to form tungsten oxide and also to obtain crystalline samples that leading to WTN with varied weight loading percentage of $0.2 \%, 0.5 \%, 0.8 \%$ and $1.1 \%$ referred to as WTN1, WTN2, WTN3 and WTN4, respectively. Table 2 summarizes the experimental conditions for 5 different samples. A schematic of the pretreatment method of titanium and process of producing WTN films on titanium foil is shown in Fig.2.

The surface morphology of all samples was characterized by field emission scanning electron microscopy (FE-SEM, Hitachi S-4160, Japan). The crystalline phases were identified by XRD (Philips XPert). Diffraction patterns were recorded at room temperature in the $2 \theta$ range of $20^{\circ}$ to $80^{\circ}$. The optical absorption of the samples was determined using a diffuse reflectance UV-visible (DRUV-Vis) spectrophotometer (JASCO V-570). The values of the band gap energy $\left(E_{\mathrm{g}}\right)$ were calculated using following equation:

$$
(\alpha h v)=A\left(h v-E_{g}\right)^{n}
$$

where, $E_{\mathrm{g}}$ is the band gap energy, $h$ is Planck's constant, $v$ is the frequency of vibration, $h v$ is the incident photon energy, $A$ is a proportional constant and $\alpha$ is the absorption coefficient per unit length ${ }^{[8]}$. The band gap values were determined by extrapolating the linear region of the plot to $h v=0$.
Table 2 Experimental parameters for the synthesis of different samples

\begin{tabular}{|c|c|c|c|}
\hline Sample & Anodizing solution & Chemical bath $^{\#}$ & $E_{\mathrm{g}} / \mathrm{eV}$ \\
\hline $\mathrm{TN}$ & $\begin{array}{l}90 \mathrm{~mL} \text { glycerol }+10 \mathrm{~mL} \mathrm{H}_{2} \mathrm{O} \\
+0.13 \mathrm{~mol} / \mathrm{L} \mathrm{NH}_{4} \mathrm{~F}(60 \mathrm{~V}, 6 \mathrm{~h} \\
\text { at RT) }\end{array}$ & - & 3.20 \\
\hline WTN1 & $\begin{array}{l}90 \mathrm{~mL} \text { glycerol }+10 \mathrm{~mL} \mathrm{H}_{2} \mathrm{O} \\
+0.13 \mathrm{~mol} / \mathrm{L} \mathrm{NH}_{4} \mathrm{~F}(60 \mathrm{~V}, 6 \mathrm{~h} \\
\text { at RT })\end{array}$ & $\begin{array}{l}\text { Soaking for } 1 \mathrm{~h} \\
\text { at } 70^{\circ} \mathrm{C}\end{array}$ & 2.70 \\
\hline WTN2 & $\begin{array}{l}90 \mathrm{~mL} \text { glycerol }+10 \mathrm{ml} \mathrm{H}_{2} \mathrm{O} \\
+0.13 \mathrm{~mol} / \mathrm{L} \mathrm{NH} \mathrm{N}_{4} \mathrm{~F}(60 \mathrm{~V}, 6 \mathrm{~h} \\
\text { at RT) }\end{array}$ & $\begin{array}{l}\text { Soaking for } 2 \mathrm{~h} \\
\text { at } 70^{\circ} \mathrm{C}\end{array}$ & 2.60 \\
\hline WTN3 & $\begin{array}{l}90 \mathrm{~mL} \text { glycerol }+10 \mathrm{~mL} \mathrm{H}_{2} \mathrm{O} \\
+0.13 \mathrm{~mol} / \mathrm{L} \mathrm{NH}_{4} \mathrm{~F}(60 \mathrm{~V}, 6 \mathrm{~h} \\
\text { at RT) }\end{array}$ & $\begin{array}{l}\text { Soaking for } 3 \mathrm{~h} \\
\text { at } 70^{\circ} \mathrm{C}\end{array}$ & 2.30 \\
\hline WTN4 & $\begin{array}{l}90 \mathrm{~mL} \text { glycerol + } 10 \mathrm{~mL} \mathrm{H}_{2} \mathrm{O} \\
+0.13 \mathrm{~mol} / \mathrm{L} \mathrm{NH}_{4} \mathrm{~F}(60 \mathrm{~V}, 6 \mathrm{~h} \\
\text { at RT) }\end{array}$ & $\begin{array}{l}\text { Soaking for } 4 \mathrm{~h} \\
\text { at } 70^{\circ} \mathrm{C}\end{array}$ & 2.15 \\
\hline
\end{tabular}

\#: Chemical bath deposition in $\mathrm{H}_{2} \mathrm{O} /$ ethanol (4:1) solution containing $0.05 \mathrm{~mol} / \mathrm{L} \mathrm{Na}_{2} \mathrm{WO}_{4} \cdot 2 \mathrm{H}_{2} \mathrm{O}$

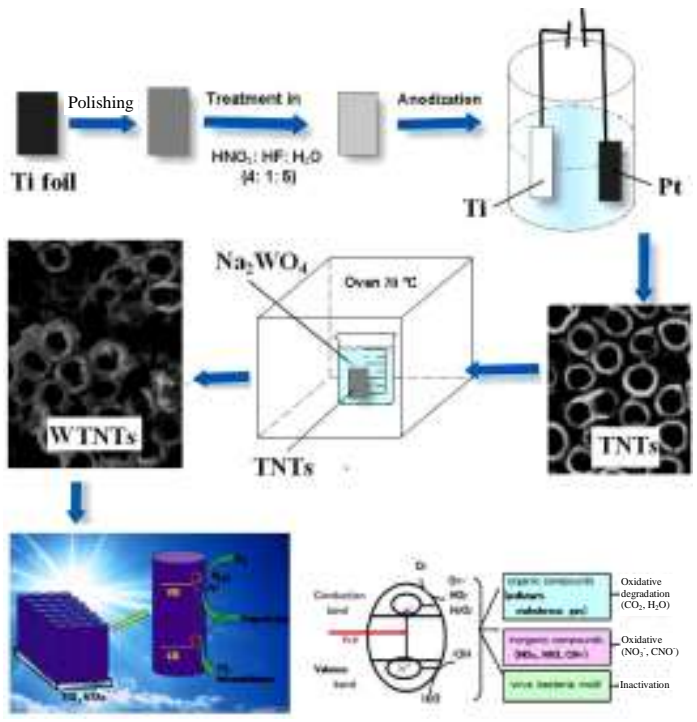

Fig.2 Schematic presentation of the pretreatment method of titanium sheets and producing process of WTN samples

Photocatalytic activity of all the samples was evaluated by degradation of the aqueous C.I. Sulphur Red 14 (CISR) under visible light irradiation. The photocatalytic reaction proceeded in a single-compartment cylindrical quartz reactor. A $200 \mathrm{~W}$ xenon lamp was used as a light source with a $420 \mathrm{~nm}$ cutoff filter to provide visible light. The luminous intensity of the xenon lamp was $100 \mathrm{~mW} / \mathrm{cm}^{2} .100 \%$ of the light was transmitted by the quartz glass as the xenon lamp shone on the samples. A fan was used to cool down the reactor tube. The experiments were performed at room temperature. The initial concentration of CISR was $10 \mathrm{mg} / \mathrm{L}$. The volume of the solution was $50 \mathrm{~mL}$. Prior to illumination, the photocatalyst sample was immersed in quartz reactor containing CISR and magnetically stirred for $2 \mathrm{~h}$ in the dark to ensure the 
establishment of an adsorption-desorption equilibrium between the photocatalyst and CISR. Then the solution was exposed to visible light irradiation under magnetic stirring for $2 \mathrm{~h}$. At each $15 \mathrm{~min}$ intervals, $5 \mathrm{~mL}$ solution was sampled and the absorbance of CISR was measured by a UV-Vis spectrophotometer.

\section{Results and Discussion}

The FE-SEM micrographs of the as-prepared samples are illustrated in Fig.3. Which are showed the top view of titania nanotube arrays decorated with $\mathrm{WO}_{3}$ nanoparticles (WTN) samples formed by chemical bath deposition. All samples display vertically ordered nanotube arrays with the internal diameter of the tubes $90 \sim 120 \mathrm{~nm}$, external diameter 120 160 $\mathrm{nm}$ and wall thickness $30 \sim 60 \mathrm{~nm}$. It can be seen that the $\mathrm{WO}_{3}$ particles are distributed on the surface of the titania nanotube and in some cases inside nanotubes (Fig.3e).

Fig. 4 shows the XRD patterns of TN and WTN samples annealed at $400{ }^{\circ} \mathrm{C}$. It confirms the presence of anatase phase of $\mathrm{TiO}_{2}$ in the samples, and the Ti peaks are due to the titanium substrate. The WTN presents peaks attributed to the metal substrate of $\mathrm{Ti}, \mathrm{TiO}_{2}$ as anatase and the formation of $\mathrm{WO}_{3}$ in the monoclinic form. The formation of tungsten oxide on the titania nanotube arrays is also confirmed through energy-dispersive X-ray spectroscopy (EDX) spectra obtained from different samples (data not reported here). In EDX
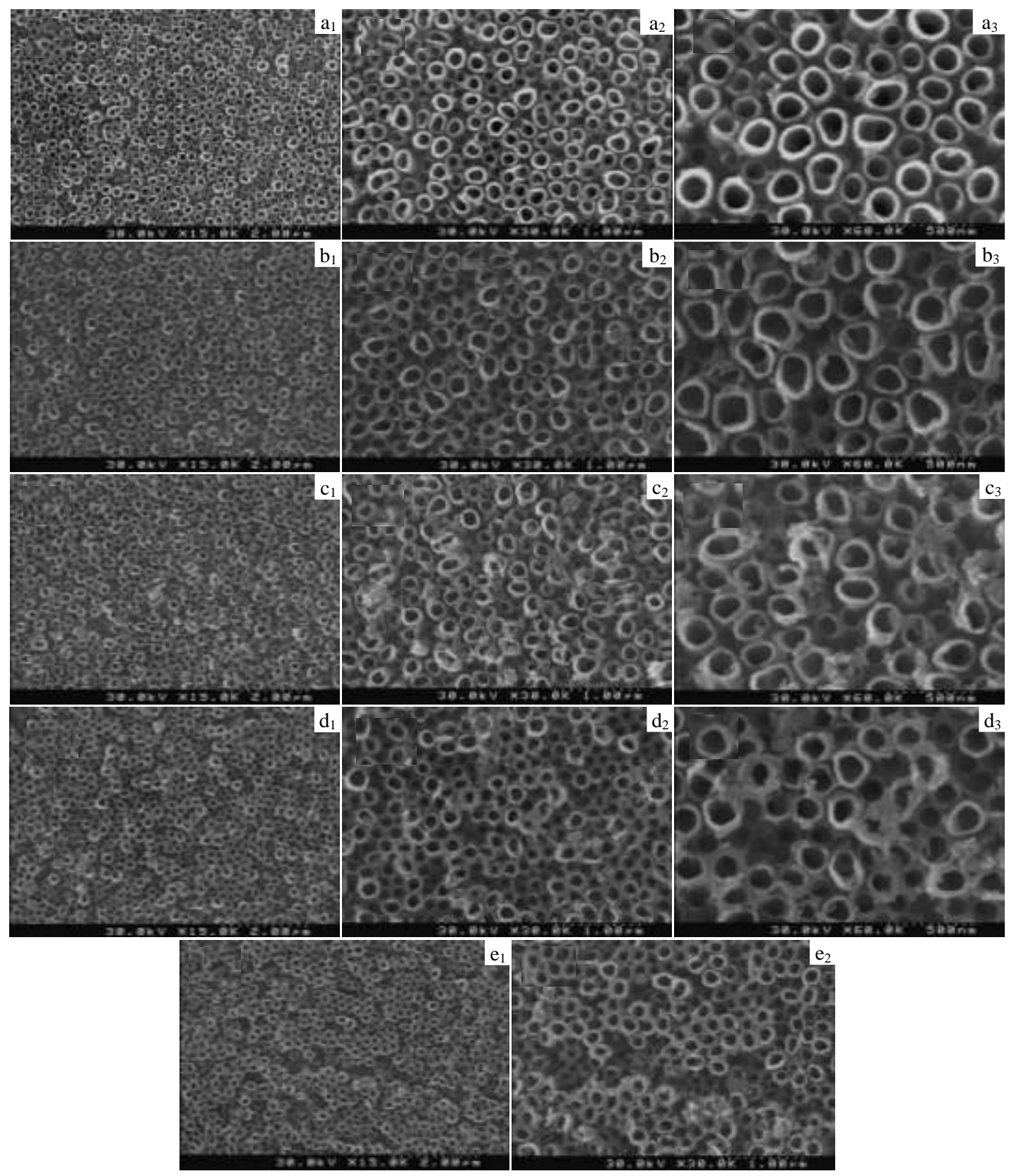

Fig.3 SEM top-view images of WTN samples with different magnifications: (a) TN, (b) WTN1, (c) WTN2, (d) WTN3, and (e) WTN4 


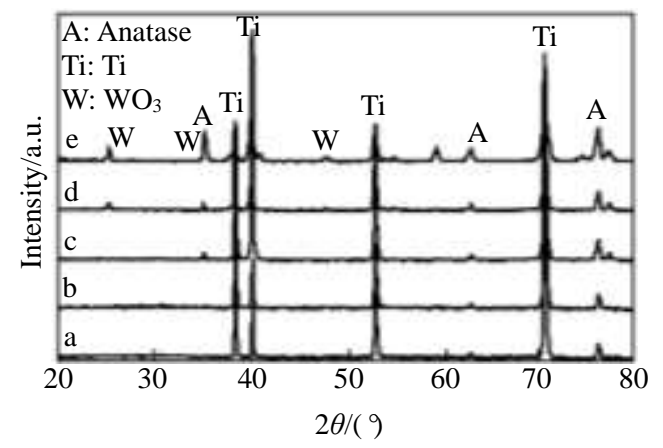

Fig.4 XRD patterns of different samples annealed at $400{ }^{\circ} \mathrm{C}$ (a: TN, b: WTN1, c: WTN2, d: WTN3, and e: WTN4)

spectrum of WTN samples, peaks of Ti, W and $\mathrm{O}$ are observed. The elemental contents of all samples are present in Table 3.

Regarding to the UV-Vis spectra, the absorption edge of WTN4 is closer to the visible light region than that of other samples (Table 2). The incorporation of $\mathrm{WO}_{3}$ extends the ability of $\mathrm{TiO}_{2}$ to respond to higher wavelengths. These results are in agreement with previous reports ${ }^{[8,9]}$ indicating that the visible shift in the absorption edge of the WTN catalyst depends on the synthesis method, the nature of the precursors, and the amount of tungsten ${ }^{[9]}$.

The photocatalytic degradation efficiency using different catalysts was evaluated under visible light irradiation based on the percent of degradation of an initial concentration of 10 $\mathrm{mg} / \mathrm{L} \mathrm{CISR} \mathrm{in} \mathrm{an} \mathrm{aqueous} \mathrm{solution.} \mathrm{The} \mathrm{first,} \mathrm{CISR} \mathrm{degra-}$ dation experiments were conducted under visible light irradiation to evaluate direct photolysis without the addition of any catalyst. The concentration of CISR remains nearly constant after $120 \mathrm{~min}$ of irradiation. Thus, no obvious degradation of CISR is observed in this time period. In addition, a dark control experiment was conducted, indicating that the adsorption of CISR onto the surface of the catalyst in the absence of visible light radiation is negligible. The photocatalysis results indicate that the photocatalytic process is very effective in the removal of CISR and it is observed that the degradation of CISR is enhanced using WTN catalysts. Fig.5 shows photocatalytic activity of different samples through degradation of CISR as a function of irradiation time with visible light. Under the irradiation of visible light, non-decorated $\mathrm{TiO}_{2}$ nanotube sample almost exhibits no

Table 3 Average elemental compositions of different samples obtained by taking ten spots in EDX analysis (at\%)

\begin{tabular}{cccccc}
\hline Sample & $\mathrm{Ti}$ & $\mathrm{O}$ & $\mathrm{W}$ & $\mathrm{C}$ & $\mathrm{F}$ \\
\hline TN & 35.3 & 51.2 & - & 1.5 & 12.0 \\
WTN1 & 35.1 & 51.0 & 0.50 & 1.3 & 12.1 \\
WTN2 & 34.8 & 50.8 & 0.90 & 1.2 & 12.3 \\
WTN3 & 34.6 & 50.5 & 1.3 & 1.4 & 12.2 \\
WTN4 & 34.2 & 49.9 & 2.4 & 1.1 & 12.4 \\
\hline
\end{tabular}
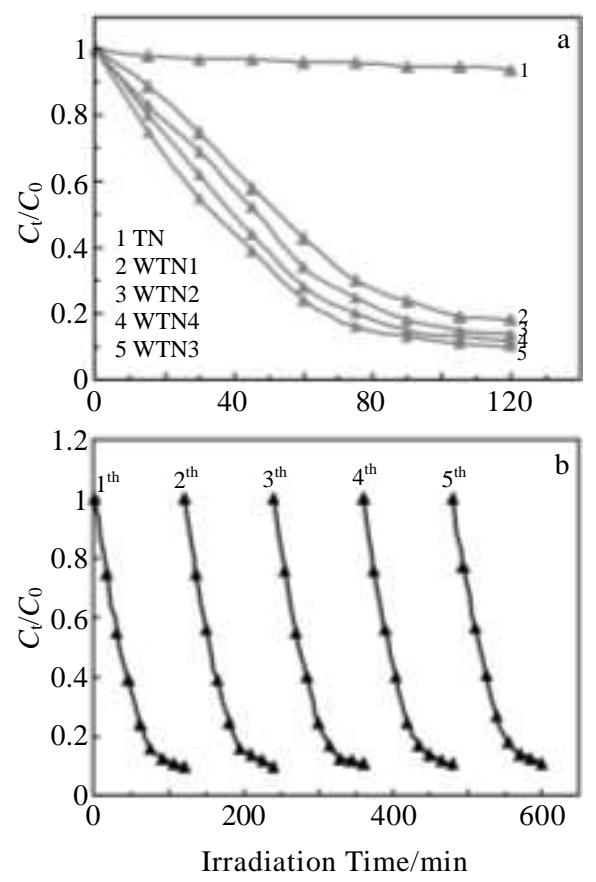

Fig.5 Photocatalytic degradation of CISR over the different samples (a) and photocatalyst stability test of WTN3 sample for photocatalytic degradation of CISR (b)

photocatalytic activity, but the WTN samples show photocatalytic activity. Curve in Fig.5a shows that the WTN3 exhibits better photocatalytic activity than other samples under visible light illumination. Also it can be seen that the photocatalytic activity of WTN3 sample is higher than that with non-decorated $\mathrm{TiO}_{2}$ sample. The higher photocatalytic activity of WTN samples can be attributed to the combined effect of several factors: the tungsten doping, the one dimensional nanostructure, and the increased light-harvesting ability (capability to absorb visible light and higher light absorption, compared to non-decorated $\mathrm{TiO}_{2}$ nanotubes).

The stability of a photocatalyst is also important to its practical application for it can be regenerated and reused. We investigated the cyclic stability of sample WTN3 by monitoring the catalytic activity during successive cycles of use. As shown in Fig.5b, after a five-cycle experiment, this catalyst exhibits similar catalytic performance without significant deactivation, revealing its high stability after multiple reuses.

\section{Conclusions}

1) $\mathrm{TiO}_{2}$ nanotubes decorated with $\mathrm{WO}_{3}$ were synthesized using an effective approach of anodizing combined by a chemical bath deposition technique. The decoration strategy is facile and cheap and tungsten oxide nanostructures could be kept on the surface and in some cases, inside of the titania nanotubes. 
2) Tungsten exists on these films. Also variation in the preparation conditions i.e. immersion time, leads to a different concentration of tungsten at the interface and change the morphology.

3) The resultant hybrid nanotubes array shows excellent photocatalytic performance. The sample WTN3 exhibits better photocatalytic activity than other samples. Also this photocatalyst shows good stability and it could be recycled several times without significant loss of its activity.

\section{References}

1 Zhong J S, Wang Q Y, Zhu X et al. J Alloy Compd[J], 2015, 641: 144

2 Momeni M M, Ghayeb Y. J Mater Sci: Mater Electron[J], 2016,
27: 3318

3 Song H, Jo K, Jung B Y et al. Nano Res[J], 2014, 7: 104

4 Momeni M M, Ghayeb Y. Ceram Int [J], 2016, 42: 7014

5 Momeni M M, Nazari Z. Ceram Int[J], 2016, 42: 8691

6 Momeni M M, Ghayeb Y. J Solid State Electrochem[J], 2016, 20: 683

7 Wang M Y, Ioccozia J, Sun L et al. Energy Environ Sci[J], 2014, 7: 2182

8 Momeni M M, Ghayeb Y. J Mol Catal A: Chem[J], 2016, 417: 107

9 Momeni M M, Mirhosseini M, Chavoshi M. Ceram Int [J], 2016, 42: 9133

10 Kamani H, Bazrafshan E, Ghanbari Ghozikali M et al. Health Scope [J], 2015, 4(2) : 22248

\title{
$\mathrm{WO}_{3}$ 修饰 $\mathrm{TiO}_{2}$ 纳米管阵列制备、表征及光催化活性
}

\author{
Mohamad Mohsen Momeni \\ (伊斯法罕理工大学, 伊斯法罕 84156-83111, 伊朗)
}

\begin{abstract}
摘 要: 利用化学浴沉积 $(\mathrm{CBD})$ 结合热解工艺制备了 $\mathrm{WO}_{3}$ 修饰 $\mathrm{TiO}_{2}$ 纳米管 $(\mathrm{WTN})$ 阵列, 且 $\mathrm{WTN}$ 阵列分布均匀。通过改变沉积时间 可调整 WTN 的铇含量。利用 SEM、EDX、XRD 对 WTN 进行了表征。结果表明, 阴极氧化后, $\mathrm{TiO}_{2}$ 纳米管生长于钛体基体上, 纳米 管的内径为 90 120 nm, 外径为 120 160 nm, 壁厚在 30 60 nm 范围, 长约 $39 \mu \mathrm{m}$ 。经 C. I. 硫化红 14 的有效去除证实, 修饰 $\mathrm{TiO}_{2}$ 纳米 管的 $\mathrm{WO}_{3}$ 增强了 $\mathrm{WTN}$ 光催化活性, 在可见光照射下, 所制备复合膜光催化活性优于未修饰纳米管阵列 (TN)。
\end{abstract}

关键词: 纳米管; 薄膜; 阳极氧化; 光催化剂

作者简介: Mohamad Mohsen Momeni, 副教授, 伊斯法罕理工大学化学系, 伊斯法罕 84156-83111, 伊朗, E-mail: mm.momeni@cc.iut.ac.ir 